\title{
Production and Characterization of a Novel Yeast Extracellular Invertase Activity Towards Improved Dibenzothiophene Biodesulfurization
}

\author{
Bruno F. Arez • Luís Alves • Susana M. Paixão
}

Received: 11 April 2014 / Accepted: 18 August 2014 /

Published online: 28 August 2014

(C) Springer Science+Business Media New York 2014

\begin{abstract}
The main goal of this work was the production and characterization of a novel invertase activity from Zygosaccharomyces bailii strain Talf1 for further application to biodesulfurization (BDS) in order to expand the exploitable alternative carbon sources to renewable sucrose-rich feedstock. The maximum invertase activity $\left(163 \mathrm{U} \mathrm{ml}^{-1}\right)$ was achieved after 7 days of Z. bailii strain Talf1 cultivation at $\mathrm{pH} 5.5-$ 6.0, $25{ }^{\circ} \mathrm{C}$, and $150 \mathrm{rpm}$ in Yeast Malt Broth with $25 \%$ Jerusalem artichoke pulp as inducer substrate. The optimum $\mathrm{pH}$ and temperature for the crude enzyme activity were 5.5 and $50{ }^{\circ} \mathrm{C}$, respectively, and moreover, high stability was observed at $30{ }^{\circ} \mathrm{C}$ for $\mathrm{pH}$ 5.5-6.5. The application of Talf1 crude invertase extract (1\%) to a BDS process by Gordonia alkanivorans strain $1 \mathrm{~B}$ at $30{ }^{\circ} \mathrm{C}$ and $\mathrm{pH} 7.5$ was carried out through a simultaneous saccharification and fermentation (SSF) approach in which $10 \mathrm{~g}^{-1}$ sucrose and $250 \mu \mathrm{M}$ dibenzothiophene were used as sole carbon and sulfur sources, respectively. Growth and desulfurization profiles were evaluated and compared with those of BDS without invertase addition. Despite its lower stability at $\mathrm{pH} 7.5$ (loss of activity within $24 \mathrm{~h}$ ), Talf1 invertase was able to catalyze the full hydrolysis of $10 \mathrm{~g} \mathrm{l}^{-1}$ sucrose in culture medium into invert sugar, contributing to a faster uptake of the monosaccharides by strain 1B during BDS. In SSF approach, the desulfurizing bacterium increased its $\mu_{\max }$ from 0.035 to $0.070 \mathrm{~h}^{-1}$ and attained a 2hydroxybiphenyl productivity of $5.80 \mu \mathrm{M} / \mathrm{h}$ in about 3 days instead of 7 days, corresponding to an improvement of 2.6 -fold in relation to the productivity obtained in BDS process without invertase addition.
\end{abstract}

Keywords Invertase activity $\cdot$ Zygosaccharomyces bailii strain Talf1 · Biodesulfurization · Gordonia alkanivorans strain 1B · SSF · Dibenzothiophene

B. F. Arez $\cdot$ L. Alves $(\bowtie) \cdot$ S. M. Paixão $(\bowtie)$

LNEG - Laboratório Nacional de Energia e Geologia, Unidade de Bioenergia, Estrada do Paço do Lumiar, 22, Lisbon 1649-038, Portugal

e-mail: luis.alves@lneg.pt

e-mail: susana.alves@lneg.pt 